\title{
Large organic orbitocranial foreign body
}

\author{
Deepsekhar Das 주, Avilasha Mohapatra, Sahil Agrawal 도 , Mandeep S Bajaj
}

Ophthalmology, Dr Rajendra Prasad Centre for Ophthalmic Sciences, All India Institute of Medical Sciences, New Delhi, India

\section{Correspondence to} Dr Deepsekhar Das; doc.deep.das@gmail.com

Accepted 14 July 2020

\section{Check for updates}

(C) BMJ Publishing Group Limited 2020. No commercial re-use. See rights and permissions. Published by BMJ.

To cite: Das D, Mohapatra A,
Agrawal S, et al. BMJ Case
Rep 2020;13:e237186.
doi:10.1136/bcr-2020-
237186

\section{DESCRIPTION}

A 32-year-old man was brought to the emergency department with a history of road traffic accident (figure 1). His attendant stated that the patient was riding a motorcycle when a truck moving in front of him carrying sugarcane sticks, came to a sudden halt and one stick entered his left eye.

On examination, the patient was found to be unconscious, his blood pressure, pulse rate and respiratory rate were within normal limits. On local examination, multiple lacerations were seen around the left eye and in the lower eyelid of the right eye. A sugarcane stick was lodged in his left orbit near the bridge of the nose. His left upper and lower eyelids were swollen and chemosed. On performing a torchlight examination, his right pupil responded briskly, however, the left eye had a fixed dilated pupil, which was not responding to light. On fundus examination, the right eye had mild disc oedema without any haemorrhages, while the left eye had a pale disc with few haemorrhages. There were no foreign bodies lodged in the fornices and both the eyeballs appeared to be intact. There was no evidence of any injury to any other part of the body.

A CT scan of the head and orbit was performed to look for the extent of the damage. It revealed a well-defined iso-dense structure in the medial aspect of left orbit associated with fracture of the medial wall of the left orbit and anterior wall of left sphenoid sinus with pneumocranium; suggestive of an organic orbitocranial foreign body (figure 2; video 1). A diagnosis of right eye indirect traumatic optic neuropathy and left orbital-cranial organic foreign body with optic nerve transection was made.

The patient underwent a craniotomy-assisted orbital foreign body removal, and the wound site was then thoroughly examined under microscope to rule out any residual foreign body and the medial canthus was repaired. It was a multidisciplinary approach involving the neurosurgery and the oculoplasty department. The foreign body was a sugarcane stalk measuring $11 \mathrm{~cm}$ in length and $1.5 \mathrm{~cm}$ in diameter (figure 3). The patient was started on topical moxifloxacin, carboxymethylcellulose, homatropine and prednisolone acetate; along with intravenous cephalosporins and prednisolone in view of right eye optic neuropathy. He was also commenced on prophylactic oral voriconazole to prevent the development of fungal infection. Post-operative recovery was uneventful. At 3 weeks follow-up, the left eye had ptosis, hypertropia and medial canthal dystopia (figure 4). Visual acuity of the right eye was $6 / 6$ and no perception of light in the left eye. Indirect ophthalmoscopy revealed normal findings in the right eye and features of optic atrophy in the left.

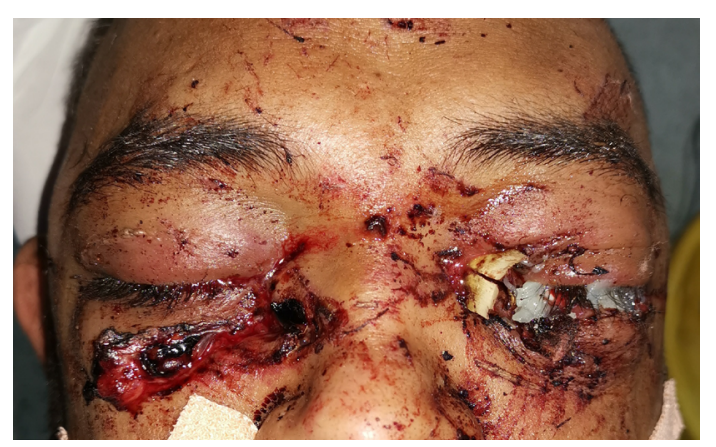

Figure 1 Clinical picture showing a foreign body embedded in the left medial orbit and right lower eyelid laceration.

Penetrating injuries to the eye are common during accidents, assault and wars; but intraorbital foreign body is a rare occurrence. ${ }^{1}$ The possibility of an object to penetrate the orbital wall and enter the intracranial cavity depends on various factors namely: energy, features of the object (tip, shape, velocity) and the angle of approach. ${ }^{2}$ There are instances where a bamboo stick as got lodged in the orbit after a person rode into a truckload of bamboo logs similar to our patient. ${ }^{3}$ In situations where the patient presents with an intraorbital foreign body, it is very important to rule out any intracranial extension. The management of such cases need a multidisciplinary approach involving both neurosurgery as well as oculoplasty departments. Organic foreign bodies present a

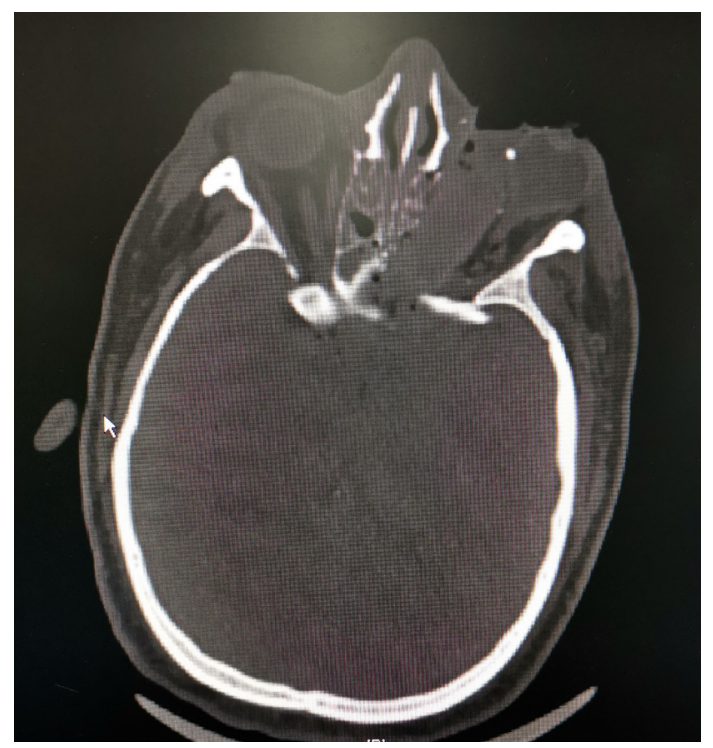

Figure 2 CT scan showing a well-defined isodense structure in the medial aspect of left orbit associated with fracture of the medial wall of the left orbit and anterior wall of left sphenoid sinus. 


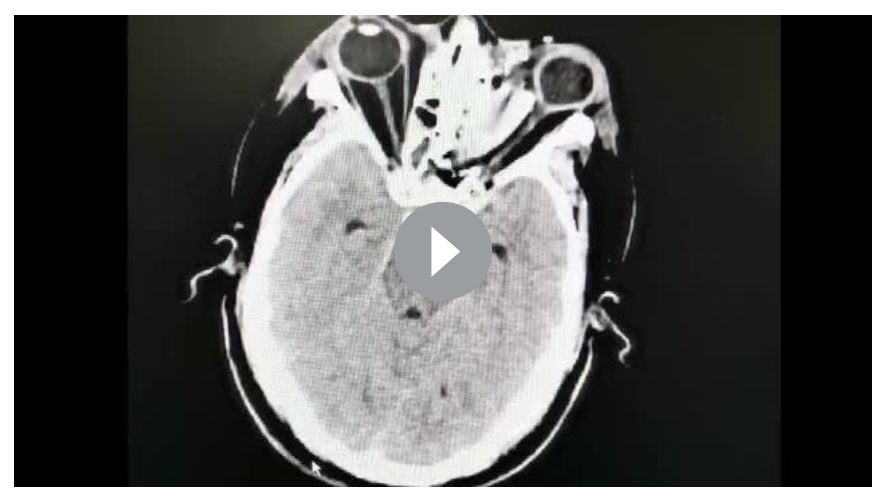

Video 1. Video of CT scan showing a large orbito-cranial foreign body.

diagnostic challenge and a thorough history taking with a meticulous physical examination is compulsory. Wounds, in many cases maybe self-sealed and camouflaged by eyebrows. ${ }^{4}$ They also have a varied appearance on different imaging modalities. ${ }^{56}$ CT scan which is the considered as the investigative modality of choice in case of any orbital foreign body; can sometimes confuse it with air or fat. ${ }^{7}$ Ultrasonography has limited role in localising the foreign body due to the interference with gas. ${ }^{8}$ Intracranial arterial injury is to be suspected when the entry wound is over the frontobasaltemporal regions, there is a bihemispheric wound trajectory, the wound trajectory is close to the circle of Willis, there is a subarachnoid haemorrhage or there is an intraventricular haemorrhage. ${ }^{9}$ Organic foreign bodies act as a good medium for bacterial growth

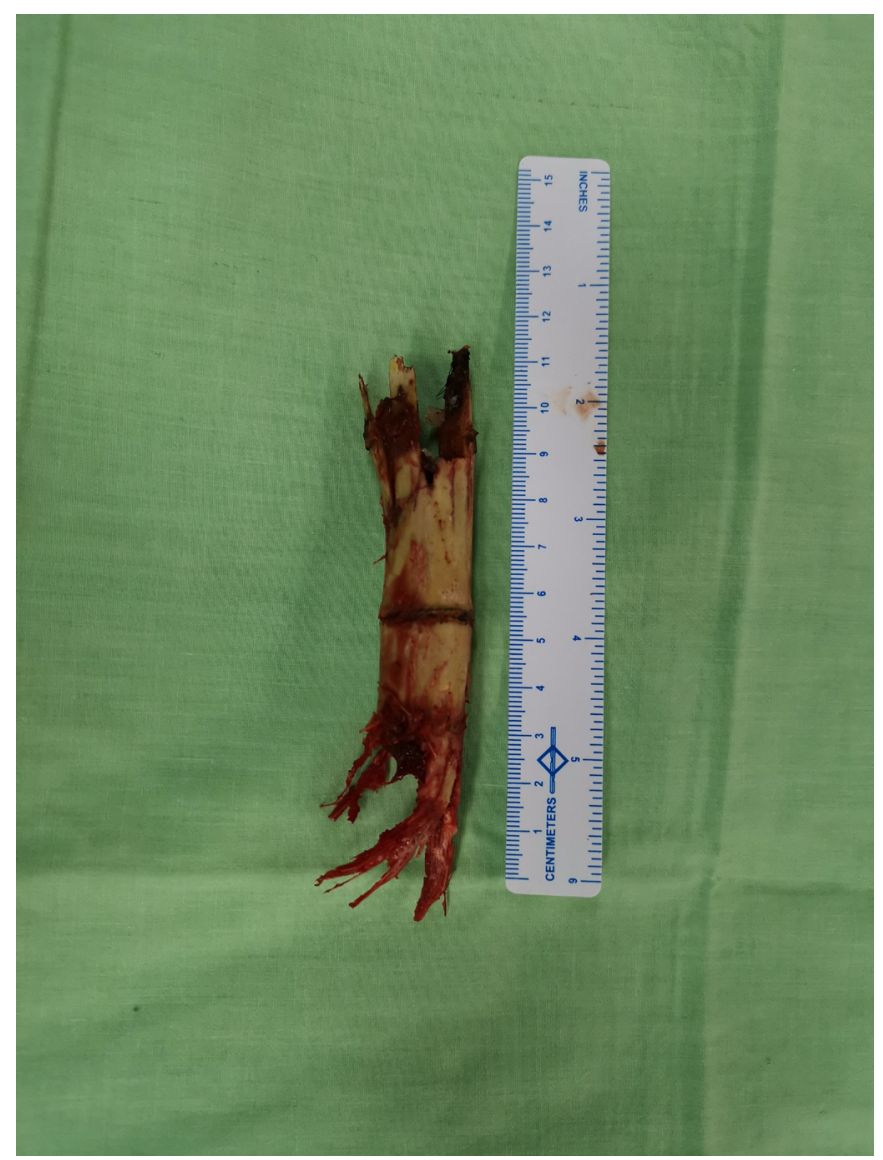

Figure 3 Image of the sugarcane foreign body measuring $11 \mathrm{~cm}$ in length and $1.5 \mathrm{~cm}$ in diameter.

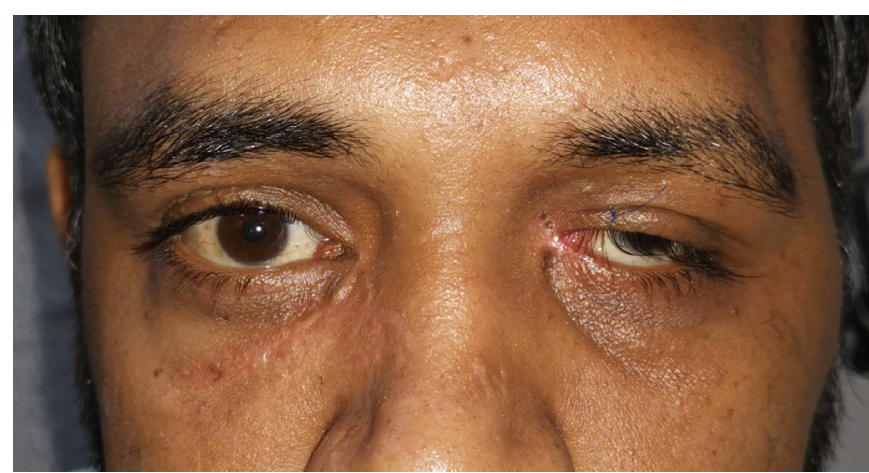

Figure 4 Clinical picture of the patient at 3 weeks follow-up showing left eye ptosis with hypertropia.

and can lead to infections and complications such as orbital cellulitis, orbital abscess, meningitis and literature suggests that such foreign bodies should be surgically removed within 12 hours of trauma to prevent them. ${ }^{10-12}$ Other adverse sequelae include neurological deficits, intracranial haemorrhage, thrombosis, proptosis, optic nerve damage complications. Cerebrospinal fluid leaks occurring following trauma usually resolve and are managed conservatively. ${ }^{12}$ The preferred antibiotic for prophylaxis are the cephalosporins. ${ }^{13}$ Organic foreign bodies can also act as a source for the development of fungal infections, and although there is no definite described prophylactic antifungal regimen for orbital organic foreign body, an antifungal should be started. ${ }^{314}$

Removal of foreign body such as wood or sugarcane stick can leave behind small residual sliver. These sometimes cause recurrent late manifestations of orbital cellulitis recalcitrant to treatment. ${ }^{15}$ In such instances, a repeat radiological examination should advised to locate the foreign body and plan the further course of management. Transcutaneous endoscopy can be performed in order to view and remove the foreign bodies with limiting the extent of surgical scar. ${ }^{16}$ To restrict the development of ophthalmic comobidities such as strabismus and ptosis, it is necessary to examine the structural damage inflicted by the foreign body at the time surgical removal and repair them. However, the result cannot be predicted as the injury to the underlying nerves can be permanent and there will be wound site inflammation and scarring. In our case, a proper wound site visualisation under the microscope aided in complete removal

Patient's perspective

I do not know how I survived this accident. I am thankful to god and whoever helped me.

\section{Learning points}

- Post-traumatic retained orbitocranial foreign body is a rare yet life-threatening situation.

- Organic foreign bodies are a diagnostic challenge and require a meticulous history taking, careful physical examination and a thorough evaluation of radiological images.

- They also are a therapeutic challenge as there is always a possibility of residual sliver to be left behind hidden which may cause inflammation and infection later.

- Managed timely and efficiently, associated mortality and morbidity can be reduced. 
of the foreign body, there was not much damage to the levator palpebrae superioris muscle, however the lacerated medial canthal tendon was repaired.

The need for postoperative steroids varies from patient to patient. Our patient had an orbitocranial foreign body with indirect traumatic optic neuropathy in the uninvolved eye. In order to salvage the vision of the right eye intravenous steroids were initiated and the patient gained normal vision on follow-up.

The patient developed exotropia on due to scarring of surrounding adnexa and even though he lost vision of his left eye, the overall outcome was satisfactory without any major neurological problem.

Contributors DD, MSB and SA participated in the diagnosis and management of the case. DD and AM participated in designing and preparing and finalising the manuscript.

Funding The authors have not declared a specific grant for this research from any funding agency in the public, commercial or not-for-profit sectors.

Competing interests None declared.

Patient consent for publication Obtained.

Provenance and peer review Not commissioned; externally peer reviewed.

ORCID iDs

Deepsekhar Das http://orcid.org/0000-0002-4446-0274

Sahil Agrawal http://orcid.org/0000-0001-6667-249X

\section{REFERENCES}

1 Nguyen VD, Singh AK, Altmeyer WB, et al. Demystifying orbital emergencies: a pictorial review. Radiographics 2017:37:947-62.
2 Baranwal VK, Gupta RP, Johri S, et al. A case of orbitocranial foreign body. Med J Armed Forces India 2016:72:82-4

3 Fasina 0, Ugalahi MO, Oluwaseyi OT, et al. Unusual intraorbital foreign bodies: a report of two cases and review of literature. Afr J Trauma 2017:6:19-22.

4 Dudani A, Pawar H, Dudani AA, et al. A challenging case of a large orbitocranial wooden foreign body in a child. Indian J Ophthalmol 2019;67:1510-2.

5 John S, Rehman T, John D, et al. Missed diagnosis of a wooden intra-orbital foreign body. Indian J Ophthalmol 2008:56:322--4.

6 Shein-Filipowicz A, Kaźmierczak R, Kostkiewicz B, et al. Itraorbital organic foreign body - radiological methods in diagnosis - case report. Pol I Radiol 2010;75:55--60.

7 Roberts CF, Leehey PJ. Intraorbital wood foreign body mimicking air at CT. Radiology 1992;185:507-8.

8 Aras MH, Miloglu O, Barutcugil C, et al. Comparison of the sensitivity for detecting foreign bodies among conventional plain radiography, computed tomography and ultrasonography. Dentomaxillofac Radiol 2010;39:72-8.

9 Bodanapally UK, Saksobhavivat N, Shanmuganathan K, et al. Arterial injuries after penetrating brain injury in civilians: risk factors on admission head computed tomography. J Neurosurg 2015;122:219-26.

10 Nasr AM, Haik BG, Fleming JC, et al. Penetrating orbital injury with organic foreign bodies. Ophthalmology 1999:106:523-32.

11 Potapov AA, Eropkin SV, Kornienko VN, et al. Late diagnosis and removal of a large wooden foreign body in the cranio-orbital region. J Craniofac Surg 1996;7:311-4.

12 Le C, Strong EB, Luu Q. Management of anterior skull base cerebrospinal fluid leaks. J Neurol Surg B Skull Base 2016;77:404-11.

13 Kazim SF, Shamim MS, Tahir MZ, et al. Management of penetrating brain injury. J Emerg Trauma Shock 2011;4:395-402.

14 Mukherjee B, Raichura ND, Alam MS. Fungal infections of the orbit. Indian J Ophthalmol 2016;64:337-45.

15 John SS, Rehman TA, John D, et al. Missed diagnosis of a wooden intra-orbital foreign body. Indian J Ophthalmol 2008;56:322-4.

16 Shah KD, Chacko SP, Patel T, et al. More to it than meets the eye: a case of retained intraorbital foreign body removed using transcutaneous orbital endoscopic surgery. BMJ Case Rep 2020;13:e233198.

Copyright 2020 BMJ Publishing Group. All rights reserved. For permission to reuse any of this content visit https://www.bmj.com/company/products-services/rights-and-licensing/permissions/

BMJ Case Report Fellows may re-use this article for personal use and teaching without any further permission.

Become a Fellow of BMJ Case Reports today and you can:

- Submit as many cases as you like

- Enjoy fast sympathetic peer review and rapid publication of accepted articles

- Access all the published articles

Re-use any of the published material for personal use and teaching without further permission

Customer Service

If you have any further queries about your subscription, please contact our customer services team on +44 (0) 2071111105 or via email at support@bmj.com.

Visit casereports.bmj.com for more articles like this and to become a Fellow 